\title{
Complication Profiles Associated with Sacral Alar lliac Screw Fixation in Patients with Adult Spinal Deformity: A Comparative Analysis to the Conventional Iliac Screw Fixation
}

\author{
Ga-On Park', Un-Yong Choi', Kyung-Hyun Kim¹, Jeong-Yoon Park, Dong-Kyu Chin ${ }^{1}$, \\ Keun-Su Kim¹, Yong-Eun Cho ${ }^{1}$ \\ ${ }^{1}$ Department of Neurosurgery, Spine and Spinal Cord Institute, Gangnam Severance Hospital, Yonsei University College of Medicine, \\ Seoul, Republic of Korea \\ ${ }^{2}$ Seoul NOW Hospital, Seongnam, Republic of Korea
}

Corresponding author:

Kyung-Hyun Kim

Department of Neurosurgery, Spine and Spinal Cord Institute, Gangnam Severance Hospital, Yonsei University College of Medicine, 211, Eonju-ro, Gangnam-gu, Seoul 06273, Republic of Korea

Tel: +82-02-2019-3397

Fax: +82-02-3461-9229

E-mail: NSKHK@yuhs.ac

\section{Un-Yong Choi}

Seoul NOW Hospital, 43, Bundangro,

Bundang-gu, Seongnam 13591,

Republic of Korea

Tel: +82-1588-2691

Fax: +82-31-788-5799

E-mail: nschoiuy@gmail.com

Received: April 23, 2021

Revised: May 14, 2021

Accepted: May 31, 2021
Objective: This study aimed to compare the radiographic and clinical outcomes between sacral alar iliac (SAI) screw fixation and conventional iliac (C) screw fixation with a particular focus on the rate of reoperation, surgical site infection (SSI), sacroiliac joint pain, instrument failure, and screw prominence. Methods: Patients who underwent sacropelvic fixation in the authors' institution from June 2011 to May 2017 were retrospectively investigated. Forty-three patients with SAI screw fixation and 25 with CI screw fixation were included. Preoperative patient and surgical characteristics and postoperative outcomes and complications were analyzed between the SAI and CI groups. Radiographic parameters were analyzed before and after surgery.

Results: Lumbosacral fusion rates showed no statistically significant difference between the SAI group and CI groups (90.7\% vs. $92.0 \%, \mathrm{p}=0.878)$. The SAI group showed a significantly good result with regard to SSI compared to the $व$ group ( $0 \%$ vs. $16 \%, p=0.016)$, but had a significantly higher rate of distal screw fracture than the CI group ( $16.3 \%$ vs. $0 \%, p=0.042)$.

Conclusion: The SAI screw fixation technique could achieve good outcomes of pain relief, deformity correction, and lumbosacral fusion rate with relatively lower complications such as the rates of reoperation, SSI, and screw prominence as compared to the CI screw fixation technique. However, distal instrument failure was observed more frequently in the SAI group, requiring further biomechanical studies.

Key Words: Lumbosacral region; Sacroiliac joint; Sacrum; Spinal fusion

\section{INTRODUCTION}

Despite all the recent advancements and development in spinal instrumentation and surgical techniques and a better understanding of the biology of spinal fusion, pseudoarthrosis, or construct failure of the lumbosacral junction continues to be a major obstacle in spinal surgery ${ }^{18,26,28)}$. The sacropelvic junction has some issues such as complex local anatomy, substantial biomechanical force, and poor bone quality that contribute to the high rates of instrumen tation-related complications ${ }^{13,20,25,29}$. Fixation of the sacropelvic spine requires additional instrumentation to overcome the complications associated with fusion ending at the S1 level.

Many sacropelvic fixation techniques have been developed: the Galveston technique and Dunn-McCarthy (S-Rod) technique, as well as the transiliac screw, intrasacral rod, iliosacral fixation, and iliac screw-based techniques, ${ }^{6,724)}$. The conventional iliac (Cl) screw fixation technique has been most commonly used to augment the sacropelvic fusion rate and reduce the mechanical failure rate. The sacral alar iliac (SAl) screw fixation technique has been introduced and is low-profile with higher biomechanical property for alternatives to Cl screw fixation.

Although there are many biomechanical and cadaveric studies on $\mathrm{SAl}$ and $\mathrm{Cl}$ screw fixation techniques, there are few direct comparative analyses of the difference in clinical outcomes between the two techniques. Therefore, the objective of this study was to compare the clinical and radiographic outcomes between $\mathrm{SAl}$ and $\mathrm{Cl}$ screw fixation techniques in a single institution, with a particular focus on the rate of reoperation, surgical site infection (SSI), sacroiliac (SI) joint pain, rod fracture, screw failure, and screw prominence.

\section{MATERIALS AND METHODS}

\section{Patient Population and Inclusion Criteria}

Institutional Review Board (IRB) approval was obtained (IRB No. 3-2017-0340). The researchers conducted a retrospective consecutive review of all patients who underwent sacropelvic fixation in their institution from June 2011 to May 2017. Sacropelvic fixation was 
performed for fusion augmentation in the cases of deformity correction operations requiring spinal fusion down to the sacrum. SAI screw fixation was performed in 79 patients and $\mathrm{Cl}$ screw fixation in 50 patients. The inclusion criteria for this study were at least one year of a follow-up period and patients having the appropriate imaging studies such as whole spine X-ray, computed tomography $(C T)$, and magnetic resonance imaging preoperatively and postoperatively. Based on these criteria, 43 of 79 patients with SAI screw fixation and 25 of 50 patients with $\mathrm{Cl}$ screw fixation were included.

\section{Preoperative Patient Demographics and Surgical Characteristics}

Patient demographics were investigated including age at operation, sex, surgical diagnosis, comorbidity such as diabetes mellitus and osteoporosis, smoking history, body mass index (BMI), bone mineral density, duration of follow-up, and preoperative and postoperative visual analog scale (VAS) for pain. Surgical characteristics were also investigated, including the history of previous lumbosacral operation, spinal level of screw fixation, postoperative complications, and reoperation. Postoperative complications included proximal junctional failure or kyphosis, distal instrument failure, rod fracture, wound dehiscence, SSI, and screw prominence. Reoperation was defined as any unplanned procedure required for the treatment of pseudoarthrosis or other complications.

\section{Radiographic Measurements}

Radiographic parameters were measured on the anteroposterior and lateral radiograph of the standing whole spine $X$-ray. Preoperative, immediately postoperative, 6 and 12 months after the surgery, and final follow-up standing whole spine X-ray were studied. The measured parameters were sagittal vertical axis (SVA), pelvic inci dence $(\mathrm{PI})$, pelvic tilt (PT), sacral slope, lumbar lordosis (LL), thoracic kyphosis, and cenvical lordosis. Proximal junctional failure was defined as "proximal junctional sagittal Cobb angle between the lower endplate of the uppermost instrumented vertebra and the upper endplate of the two supra-adjacent vertebrae $\geq 10^{\circ}$ and at least $10^{\circ}$ greater than the preoperative measurement ${ }^{14)}$. Unlike proximal junctional problems, there was no consensus on the definition of distal instrumentation or lumbo-sacro-pelvic fixation failure. With reference to previous studies ${ }^{3,5,11)}$, distal instrumentation failure was defined as breakage of the SAl or Cl screws, halo formation around the screw, or screw pullout. If patients had focal wound dehiscence or tenderness on the buttock areas directly over the SAl or $\mathrm{Cl}$ screw head immediately after the surgery, they were considered symptomatic screw prominence. Fusion status was assessed by CT scan one year after the surgery and the outcome was expressed as the grading system that was previously used in other studies (Table 1).

\section{Surgical Techniques}

The step-by-step procedures for the $\mathrm{Cl}$ and SAl screw fixation techniques are described in detail in previous studies ${ }^{2,17,25)}$ and will be discussed briefly herein. For the $\mathrm{Cl}$ screw fixation technique, a simple posterior midline incision is used, followed by an additional dissection of the posterior superior iliac spine that will be the entry point of the screw. A separate skin incision was not used for the insertion of the iliac screws. Before inserting the screw, a portion of bone at the entry point was removed by performing osteotomy to create space to minimize the prominence of the screw head. The screw must be placed between the inner table and the outer table of the iliac bone and the trajectory of the screw directed with an angulation between $20^{\circ}$ to $45^{\circ}$ caudally and $30^{\circ}$ to $45^{\circ}$ laterally. For SAl screw insertion, a simple posterior midline incision was made, and the muscle layer was dissected subperiosteally to expose the sacral bone. To preserve muscle coverage over the instrumentation, subperiosteal dissection of the sacrum was limited to the entry point located 2 to $3 \mathrm{~mm}$ caudal and 2 to $3 \mathrm{~mm}$ lateral to the neural foramen of S1. The SAl screw was directed toward the greater trochanter, rostral to the sciatic notch, and angulation was usually $40^{\circ}$ lateral in the axial plane and $40^{\circ}$ caudal in the sagittal plane; the exact trajectory was determined based on the preoperative CT and the screw was generally placed under intraoperative fluoroscopic guidance. This trajectory crosses the $\mathrm{Sl}$ joint and the screw penetrates three cortical surfaces. The tip of the screw is engaged in the dense bone above the sciatic notch.

\section{Statistical Analysis}

Intergroup comparison of categorical variables was achieved using Fisher's exact test. The unpaired t-test was used to analyze continuous variables. Data were presented as the mean \pm standard deviation unless specified. Moreover, the Mann-Whitney $U$ test was used to analyze nonparametric continuous variables. The Statistical

Table 1. Fusion grading system

\begin{tabular}{clll}
\hline \hline Grade & \multicolumn{1}{c}{ Classification } & \multicolumn{1}{c}{ Anterior fusion criteria } & \multicolumn{1}{c}{ Posterolateral fusion criteria } \\
\hline I & Definite fusion & Fused with remodeling and trabeculae & $\begin{array}{l}\text { Solid trabeculated transverse process and facet fusions } \\
\text { bilaterally }\end{array}$ \\
II $\quad$ Probable fusion & $\begin{array}{l}\text { Graft intact, not fully remodeled and incorporated } \\
\text { through; no lucency }\end{array}$ & $\begin{array}{l}\text { Thick fusion mass on one side; difficult to visualize on } \\
\text { the other }\end{array}$ \\
III $\quad \begin{array}{l}\text { Probable nonunion } \\
\text { Graft intact, but definite lucency at top or bottom }\end{array}$ & $\begin{array}{l}\text { Possible lucency or defect in the fusion mass } \\
\text { IV } \quad \text { Definite nonunion }\end{array}$ & Resorption of bone graft and collapse & Definite resorption of graft with fatigue of instrumentation
\end{tabular}


Package for the Social Sciences software (version 20.0; SPSS Inc., Chicago, IL, USA) was used for all statistical analyses. A p-value of less than 0.05 was considered statistically significant.

\section{RESULTS}

\section{Baseline Characteristics and Surgical Outcomes}

The mean duration of follow-up was $640 \pm 244$ days vs. $627 \pm$ 282 days (SAl group vs. $\mathrm{Cl}$ group); the mean age of patient was $65.3 \pm 9.0$ years vs. $60.6 \pm 13.5$ years (range, 28-79 years); and the mean number of screw fixation levels was $7.3 \pm 2.1$ segments vs. 7.6 \pm 3.1 segments (range, 3-14 segments) (Table 2). The predominant diagnoses were adult spinal degenerative deformity, iatrogenic flat back syndrome, and secondary acquired kyphosis.
Secondary acquired kyphosis included post-traumatic and post-infectious kyphosis.

Regarding baseline patient demographics, there were no statistically significant differences in age, sex, BMl, duration of follow-up, smoking, diabetes mellitus, osteoporosis, and previous spinal surgery between the two groups. In both groups, the SVA, LL, PT, and PILL improved after surgery compared to before surgery, but no statistically significant difference was observed between the two groups (Table 3). Lumbosacral fusion rates showed no statistically significant difference between the SAl group and the $\mathrm{Cl}$ group $(90.7 \%$ vs. $92.0 \%, p=0.878$ ) (Table 1, 4). There were improvements in the VAS for pain compared to preoperative values, but no statistically significant differences in the $\mathrm{SAl}$ and $\mathrm{Cl}$ groups (6.7 \pm 1.6 vs. $1.6 \pm$ $1.4, p<0.01 ; 7.2 \pm 1.3$ vs. $2.2 \pm 1.3, p<0.01$, respectively) (Table 4).

Table 2. Patient demographics and surgical characteristics in SAl group and $\mathrm{Cl}$ group

\begin{tabular}{lccc}
\hline \hline & SAl group $(\mathrm{n}=43)$ & $\mathrm{Cl}$ group $(\mathrm{n}=25)$ & $\mathrm{p}$-value \\
\hline Age (year) & $65.3 \pm 9.0$ & $60.6 \pm 13.5$ & 0.131 \\
Male/Female & $8 / 35$ & $4 / 21$ & $>0.999$ \\
BMI (kg/m) & $24.0 \pm 3.6$ & $23.4 \pm 2.7$ & 0.491 \\
Duration of follow-up (month) & $35.6 \pm 12.5$ & $35.2 \pm 14.2$ & 0.986 \\
No. of screw fixation levels (segment) & $7.3 \pm 2.1$ & $7.6 \pm 3.1$ & 0.647 \\
Smoking & $4(9.3 \%)$ & $1(4.0 \%)$ & 0.643 \\
Diabetes mellitus & $8(18.6 \%)$ & $3(12.0 \%)$ & 0.518 \\
Osteoporosis* & $14(32.6 \%)$ & $8(32.0 \%)$ & 0.799 \\
Previous spinal surgery & $25(58.1 \%)$ & $15(60.0 \%)$ & 0.761 \\
Surgical diagnosis & & & 0.227 \\
$\quad$ latrogenic flat back & $17(39.5 \%)$ & $10(40.0 \%)$ & \\
Deformity & $23(53.5 \%)$ & $10(40.0 \%)$ & \\
Secondary acquired kyphosis & $3(7.0 \%)$ & $5(20.0 \%)$ & \\
\hline
\end{tabular}

The data is presented as number (\%) or mean \pm standard deviation.

SAl: sacral alar iliac; $\mathrm{Cl}$ : conventional iliac; BMl: body mass index.

*Bone mineral density $<-2.5$.

Table 3. Radiographic parameters of sagittal alignment before and after surgery

\begin{tabular}{|c|c|c|c|c|c|c|c|c|c|}
\hline & \multicolumn{3}{|c|}{ Preoperative } & \multicolumn{3}{|c|}{ Postoperative } & \multicolumn{3}{|c|}{ Final follow-up } \\
\hline & SAl group & $\mathrm{Cl}$ group & p-value & SAl group & $\mathrm{Cl}$ group & $\mathrm{p}$-value & SAl group & Cl group & $\mathrm{p}$-value \\
\hline SVA & $101.0 \pm 58.4$ & $111.1 \pm 84.1$ & 0.657 & $35.2 \pm 45.7$ & $31.3 \pm 42.3$ & 0.775 & $66.0 \pm 44.5$ & $65.0 \pm 46.3$ & 0.941 \\
\hline PI-LL & $44.7 \pm 18.7$ & $46.5 \pm 28.0$ & 0.772 & $10.4 \pm 12.8$ & $15.1 \pm 11.4$ & 0.217 & $20.7 \pm 15.3$ & $20.9 \pm 12.6$ & 0.957 \\
\hline LL & $7.6 \pm 21.4$ & $11.7 \pm 27.3$ & 0.543 & $40.8 \pm 13.4$ & $40.6 \pm 15.1$ & 0.964 & $31.7 \pm 14.5$ & $35.4 \pm 15.3$ & 0.391 \\
\hline SS & $20.6 \pm 11.5$ & $23.2 \pm 13.1$ & 0.464 & $30.6 \pm 11.5$ & $30.6 \pm 10.6$ & 0.993 & $26.5 \pm 9.8$ & $29.2 \pm 9.5$ & 0.333 \\
\hline PT & $32.0 \pm 10.1$ & $34.9 \pm 14.6$ & 0.383 & $20.6 \pm 11.0$ & $24.8 \pm 8.4$ & 0.193 & $26.0 \pm 10.2$ & $27.1 \pm 9.9$ & 0.694 \\
\hline PI & $52.3 \pm 14.0$ & $58.2 \pm 13.6$ & 0.145 & $51.2 \pm 13.5$ & $55.7 \pm 13.9$ & 0.279 & $52.4 \pm 13.3$ & $56.3 \pm 14.1$ & 0.321 \\
\hline TK & $13.2 \pm 11.6$ & $21.8 \pm 16.6$ & 0.062 & $23.3 \pm 12.2$ & $22.3 \pm 20.7$ & 0.821 & $26.6 \pm 14.4$ & $30.1 \pm 16.2$ & 0.412 \\
\hline $\mathrm{CL}$ & $17.0 \pm 11.4$ & $19.9 \pm 16.5$ & 0.513 & $13.4 \pm 10.4$ & $12.85 \pm 16.4$ & 0.868 & $18.8 \pm 12.2$ & $15.2 \pm 15.5$ & 0.344 \\
\hline
\end{tabular}

The data is presented as mean \pm standard deviation.

SVA: sagittal vertical axis; PI: pelvic incidence; LL: lumbar lordosis; SS: sacral slope; PT: pelvic tilt; TK: thoracic kyphosis; CL: cervical lordosis; SAl: sacral alar iliac; $\mathrm{Cl}$ : conventional iliac. 


\section{Postoperative Complications}

There were no statistically significant differences between the $\mathrm{SAl}$ group and $\mathrm{Cl}$ group with respect to rod fracture, wound dehiscence, and screw prominence. The rate of reoperation, one of the major complications, did not show any statistically significant difference between the two groups (16.3\% vs. $28.0 \%, p=0.270$ ). Additionally, the rate of proximal junctional failure and proximal junctional kyphosis was not different between the two groups statistically. The SAl group had a significantly higher rate of distal screw fracture than the $\mathrm{Cl}$ group (16.3\% vs. 0\%, $\mathrm{p}=0.042$ ) (Fig. 1). The SAI group demonstrated a good result regarding SSI compared to the $\mathrm{Cl}$ group (0\% vs. $16 \%, p=0.016$ ) (Table 5).

\section{Patterns of Distal Instrument Failure and Wound Complications}

All of the distal instrument failures occurred in the SAl group except one case of peri-screw halo formation in the $\mathrm{Cl}$ group. Among eight patients with complications in the SAl group, seven patients experienced distal screw fractures. The screw fracture occurred in the junction between the head of the screw and the neck of the screw shaft in all patients. The duration of screw fracture was $300 \pm$ 30 days (range, 5-29 months). Among these seven patients, pseudoarthrosis in the lumbosacral area was Grade I in two cases, Grade II in two cases, and Grade III in three cases. Inter-group analyses

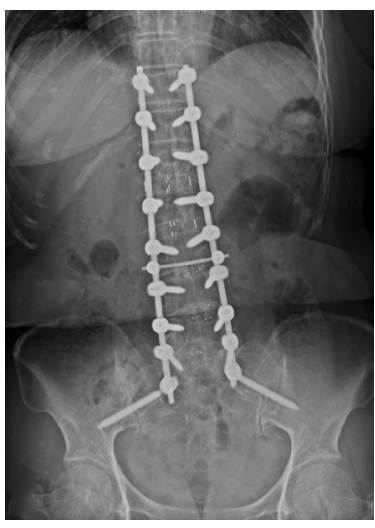

Fig. 1. A 67-year-old female patient with lumbar degenerative kyphosis showed screw fracture of right S2 alar iliac screw at 14 months after operation. The screw fracture occurred in the junction between the head and the neck of the screw.

Table 4. Preoperative and postoperative VAS score and lumbosacral fusion status in SAl group and $\mathrm{Cl}$ group

\begin{tabular}{lccc}
\hline \hline & SAl group $(\mathrm{n}=43)$ & $\mathrm{Cl}$ group $(\mathrm{n}=25)$ & $\mathrm{p}$-value \\
\hline Preoperative VAS & $6.7 \pm 1.6$ & $7.2 \pm 1.3$ & $0.207^{+}$ \\
Postoperative VAS & $1.6 \pm 1.4$ & $2.2 \pm 1.3$ & $0.167^{+}$ \\
Change in VAS & $5 \pm 1.8^{*}$ & $5 \pm 1.5^{*}$ & $0.740^{+}$ \\
L5-S1 fusion status & & & $0.878^{+}$ \\
Grade I & $19(44.2 \%)$ & $9(36.0 \%)$ & \\
Grade II & $20(46.5 \%)$ & $14(56.0 \%)$ & \\
Grade III & $4(9.3 \%)$ & $2(8.0 \%)$ & \\
Grade IV & $0(0.0 \%)$ & $0(0.0 \%)$ & \\
\hline
\end{tabular}

The data is presented as number (\%) or mean \pm standard deviation.

VAS: visual analog scale; SAl: sacral alar iliac; Cl: conventional iliac.

${ }^{*} \mathrm{p}<0.01$ according to paired $t$-test between preoperative and postoperative values. ${ }^{\dagger} \mathrm{p}$-value according to compared between groups.

Table 5. Complication profiles of SAl group and $\mathrm{Cl}$ group

\begin{tabular}{lccc}
\hline \hline & SAl group $(\mathrm{n}=43)$ & $\mathrm{Cl}$ group $(\mathrm{n}=25)$ & $\mathrm{p}$-value \\
\hline Reopeartion & $7(16.3 \%)$ & $7(28.0 \%)$ & 0.270 \\
Proximal junctional failure & $3(7.0 \%)$ & $1(4.0 \%)$ & $>0.999$ \\
Proximal junctional kyphosis & $17(39.5 \%)$ & $10(40.0 \%)$ & 0.969 \\
Distal instrument failure & & & 0.242 \\
Screw fracture & $7(16.3 \%)$ & $0(0 \%)$ & $0.042^{*}$ \\
Halo formation & $1(2.3 \%)$ & $1(4.0 \%)$ & $>0.999$ \\
Pullout & $0(0 \%)$ & $0(0 \%)$ & $>0.999$ \\
Rod fracture & $8(18.6 \%)$ & $1(4.0 \%)$ & 0.139 \\
Surgical site infection & $0(0 \%)$ & $4(16.0 \%)$ & $0.016^{*}$ \\
Wound dehiscence & $0(0 \%)$ & $2(8.0 \%)$ & 0.132 \\
Screw prominence & $1(2.3 \%)$ & $2(8.0 \%)$ & 0.550 \\
\hline SAl: saco
\end{tabular}

SAl: sacral alar iliac; Cl: conventional iliac.

*Statistical significance, $p<0.05$. 
between the distal screw fracture group and the non-distal screw fracture group were also performed. The rate of lumbosacral pseudoarthrosis (Grades III, IV) was higher in the distal screw fracture group compared to the non-distal screw fracture group, but there was no statistical significance ( $28.6 \%$ vs $6.6 \%, p=0.112)$. The improvements of SVA, LL, PT, and PI-LL after surgery did not show statistically significant differences between the two groups. All screws used in spinopelvic screw fixation were poly-axial and had diameters ranging from 7.5 to $8.5 \mathrm{~mm}$, and their lengths ranged from 80 to $90 \mathrm{~mm}$. There was no statistically significant difference between the two groups.

Regarding the two patients with wound dehiscence and the four patients with SSI in $\mathrm{Cl}$ groups, the lumbosacral area was the main area for complications. One patient with wound dehiscence had a flap graft surgery performed by a plastic surgeon in the institute. Patients with SSI were initially treated with antibiotics including vancomycin and third-generation cephalosporin for several days. If antibiotic treatment was not working based on laboratory results, the wound was opened and irrigated with normal saline and betadine-mixed saline. Gentamycin-mixed saline was added in one patient.

\section{DISCUSSION}

Sacropelvic fixation remains a challenging concept in spinal operation in spite of ongoing developments to improve distal fixation and maintain the stability of constructs in thoracolumbar operation. Sacropelvic fixation is used in spinal operations for the following two purposes: (1) to improve the correction of deformity especially in cases when the apex is located in the lumbar spine; and (2) to stabilize the lumbosacral junction to facilitate arthrodesis ${ }^{211}$. While various surgical instruments and methods have been developed, iliac screw fixation and SAI screw fixation have recently attracted attention. Sponseller et al. ${ }^{27}$ and Ishida et al. ${ }^{177}$ reported that a better pelvic obliquity correction could be achieved by using the SAl screw fixation technique without postoperative complications such as deep infections, vascular or neurologic complications, anchor migration, implant prominence, skin breakdown, medial pelvic wall violation, or screw pullout. The stability and safety of SAl screw fixation are supported by previous research studies that assessed biomechanical and clinical outcomes ${ }^{12,17,25,27}$. Similar results were observed in the current study's results. The rate of SSI was significantly lower in the SAl group than in the $\mathrm{Cl}$ group. Additionally, both groups showed appropriate lumbosacral fusion rates, and pseudoarthrosis and proximal junctional kyphosis and failure were not statistically signi- ficantly different between the two groups.

The rate of SSI was previously reported to be lower in the SAI screw fixation than the $\mathrm{Cl}$ screw fixation according to several metaanalyses $^{12,16,19}$. It is explained because an additional dissection of the posterior superior iliac spine is required to insert a $\mathrm{Cl}$ screw. Likewise, the rate of SSI was significantly lower in the SAI group in this study, and the rates of wound dehiscence, screw prominence, and reoperation were lower in the SAl group although they were not statistically significant. Screw prominence, as well as additional soft tissue dissections for $\mathrm{Cl}$ screw entry point, is believed to be one of the causes of $\mathrm{SSI}^{8}$. It is presumed that screw prominence puts abnormal pressure on the dissected tissue between the skin and the screw head and inhibits wound healing which can lead to infection.

Some results in this study were different than the findings of previous studies. For instance, the rate of distal screw fracture was higher in the SAl group with a statistically significant difference compared to the $\mathrm{Cl}$ group. These results are difficult to explain based on the results of previous biomechanical studies in which SAl screw fixation provided superior pullout strengths ${ }^{23)}$ and reduced the lumbar (L1-L5) and lumbosacral (L5-SI) ranges of motion compared to Cl screw fixation ${ }^{1)}$. OBrien et al. ${ }^{25}$ reported that biomechanical strength between SAI screws with two lengths $(65$ and $80 \mathrm{~mm})$ and $90-\mathrm{mm}$ iliac screws was equivalent in seven human cadavers. Only one study ${ }^{27}$ reported an asymptomatic fracture of the neck with a 7-mm SAl screw at the two-year follow-up. The authors explained that the $\mathrm{SI}$ joints are amphiarthrodial, and that fractures of SAl screws canoccur in the long term. Zhu et al. ${ }^{30)}$ recommended that an abun dant bone graft should be applied to the SI joint area to avoid this phenomenon. Based on those findings, the authors assumed that distal screw fracture could occur more frequently in the SAI group than in the $\mathrm{Cl}$ group. Therefore, when using the SAl screw, they recently performed intensive bone grafting on the lumbosacroiliac area. All distal screw fractures occurred in six months (ranges, 6-16 months) after surgery, and some degree of spinal fusion had already progressed, which did not directly affect the VAS score and lumbosacral fusion rates. However, this fatiguetype implant fracture, due to the motion of the $\mathrm{Sl}$ joint, needs future study to more precisely understand the phenomenon.

All screw fractures occurred at the specific site between the head of the screw and the neck of the screw shaft in the SAl group. In the case of SAI screw fixation, the acute angle develops between the screw head and the shaft of the screw. The head-shaft angulation of the screw increases the stress on the screw head and leads to screw fracture between the head and the shaft neck". Also, according to the finite element model analysis ${ }^{14)}$, the stress increased around the screw head when the rod and the SAl screw were angled 30 degrees compared to perpendicular. To prevent this problem, the use of mono-axial screws or larger diameter screws can be considered $^{9,14)}$.

Rod fractures were more common in the SAl group, but there was no statistically significant difference between the two groups. Rod fractures occurred in three cases at $L 3 / 4$, three cases at $L 4 / 5$, and two cases at $L 5 / S 1$ in the SAl group and one case at $L 4 / 5$ in the $\mathrm{Cl}$ group. A previous study using the biomechanical finite element model reported that fusion of the $\mathrm{SI}$ joint increased the motion of the lumbosacral (L5-SI) segment, and explained that rigid fixation of a motion segment resulted in increased stress on the adjacent segments ${ }^{22}$. Likewise, in the SAl group of this study, it is assumed that the fusion of $\mathrm{Sl}$ joint creates motion stresses on the lumbosacral segment and consequently leads to rod fractures. On the other hand, two-rod constructs are known to have less stiffness 
than multiple-rod constructs, which is related to rod fractures ${ }^{10,15}$. In this study, two-rod constructs were 12 and multiple-rod constructs were 13 in the $\mathrm{Cl}$ group and 34 and nine in the SAl group, respectively. The authors suggest that the risk of rod fracture would be increased because of the rigid fixation of the $\mathrm{SI}$ joint and the high rate of two-rod constructs in the SAl group.

The causes of reoperation involved three cases of proximal junctional failure, three cases of rod fracture, and one case of screw prominence in the SAl group and one case of proximal junctional failure, one case of rod fracture, two cases of pseudoarthrosis, one case of screw reposition, and two cases of wound problems in the $\mathrm{Cl}$ group. In the $\mathrm{Cl}$ group, postoperative antibiotics were used for a long time due to wound problems, and the patients had to stay in the hospital and eventually went through reoperation. In this study, there was no statistically significant difference in reoperation rate between the two groups. However, as in other studies, the SA group showed a lower rate of reoperation and proper fusion rate compared to the $\mathrm{Cl}$ group.

This study had several limitations. The main limitation was that the authors selected the patient's operative method according to the propensity of the surgeon. Other limitations apply to this study as well, such as its single-center, retrospective nature and the relatively small sample size. As such, the results of this study warrant the need for larger prospective, multicenter studies to further extrapolate findings to future patient care involving complex sacropelvic fixation.

\section{CONCLUSION}

The SAl group and the $\mathrm{C}$ group achieved pain relief and functional recovery. The SAl screw fixation technique was relatively uncomplicated and resulted in good outcomes compared to the $\mathrm{Cl}$ screw fixation in the rates of reoperation, SSI, wound dehiscence, and symptomatic screw prominence, whereas the rates of lumbosacral pseudoarthrosis and proximal junctional kyphosis and failure were similar in both groups. However, distal screw fracture was more likely to be observed with the SAI screw fixation technique, so prospective and biomechanical studies of the SAl and $\mathrm{Cl}$ screw fixation techniques are needed.

\section{CONFLICTS OF INTEREST}

No potential conflict of interest relevant to this article was reported.

Kyung-Hyun Kim and Un-Yong Choi contributed equally to this work and should be considered co-corresponding authors.

\section{REFERENCES}

1. Camisa W, Bess S, Yi S, Washiya AS, Leasure JM, Burton DC, et al.: Biomechanical demands on S2AI sacral and pelvic instrumentation in long fusion constructs with and without interbody supplementation. Spine J 14:S166, 2014

2. Chang TL, Sponseller PD, Kebaish KM, Fishman EK: Low profile pelvic fixation: Anatomic parameters for sacral alar-iliac fixation versus traditional iliac fixation. Spine (Phila Pa 1976) 34:436-440, 2009

3. Cho KJ, Suk SI, Park SR, Kim JH, Choi SW, Yoon YH, et al.: Arthrodesis to L5 versus S1 in long instrumentation and fusion for degenerative lumbar scoliosis. Eur Spine J 18:531537, 2009

4. Cho SK, Shin JI, Kim YJ: Proximal junctional kyphosis following adult spinal deformity surgery. Eur Spine J 23:27262736, 2014

5. Cho W, Mason JR, Smith JS, Shimer AL, Wilson AS, Shaffrey CI, et al.: Failure of lumbopelvic fixation after long construct fusions in patients with adult spinal deformity: Clinical and radiographic risk factors: clinical article. J Neurosurg Spine 19:445-453, 2013

6. Dayer R, Ouellet JA, Saran N: Pelvic fixation for neuromuscular scoliosis deformity correction. Curr Rev Musculoskelet Med 5:91-101, 2012

7. Desrochers-Perrault F, Aubin CE, Wang X, Schwend RM: Biomechanical analysis of iliac screw fixation in spinal deformity instrumentation. Clin Biomech (Bristol, Avon) 29:614621, 2014

8. Elder BD, Ishida W, Lo SL, Holmes C, Goodwin CR, Kosztowski TA, et al.: Use of S2-alar-iliac screws associated with less complications than iliac screws in adult lumbosacropelvic fixation. Spine (Phila Pa 1976) 42:E142-E149, 2017

9. Guler UO, Cetin E, Yaman O, Pellise F, Casademut AV, Sabat $\mathrm{MD}$, et al.: Sacropelvic fixation in adult spinal deformity (ASD); A very high rate of mechanical failure. Eur Spine J 24:10851091, 2015

10. Han S, Hyun SJ, Kim KJ, Jahng TA, Lee S, Rhim SC: Rod stiffness as a risk factor of proximal junctional kyphosis after adult spinal deformity surgery: Comparative study between cobalt chrome multiple-rod constructs and titanium alloy tworod constructs. Spine J 17:962-968, 2017

11. Harimaya K, Mishiro T, Lenke LG, Bridwell KH, Koester LA, Sides BA: Etiology and revision surgical strategies in failed lumbosacral fixation of adult spinal deformity constructs. Spine (Phila Pa 1976) 36:1701-1710, 2011

12. Hasan MY, Liu G, Wong HK, Tan JH: Postoperative complications of S2AI versus iliac screw in spinopelvic fixation: A meta-analysis and recent trends review. Spine J 20:964-972, 2020

13. Hoernschemeyer DG, Pashuck TD, Pfeiffer FM: Analysis of the $s 2$ alar-iliac screw as compared with the traditional iliac screw: does it increase stability with sacroiliac fixation of the spine? Spine J 17:875-879, 2017

14. Hyun SJ, Kim KJ: Durability and failure types of S2-alar-iliac screws: A finite element analysis study. J Adv Spine Surg 10: 33-38, 2020

15. Hyun SJ, Lenke LG, Kim YC, Koester LA, Blanke KM: Comparison of standard 2-rod constructs to multiple-rod constructs for fixation across 3-column spinal osteotomies. Spine (Phila Pa 1976) 39:1899-1904, 2014

16. Ilyas $\mathrm{H}$, Place $\mathrm{H}$, Puryear A: A comparison of early clinical and radiographic complications of iliac screw fixation versus S2 alar iliac (S2AI) fixation in the adult and pediatric populations. J Spinal Disord Tech 28:E199-E205, 2015 
17. Ishida W, Elder BD, Holmes C, Goodwin CR, Lo SF, Kosztowski TA, et al.: S2-alar-iliac screws are associated with lower rate of symptomatic screw prominence than iliac screws: Radiographic analysis of minimal distance from screw head to skin. World Neurosurg 93:253-260, 2016

18. Kebaish KM: Sacropelvic fixation: Techniques and complications. Spine (Phila Pa 1976) 35:2245-2251, 2010

19. Keorochana G, Arirachakaran A, Setrkraising K, Kongtharvonskul J: Comparison of complications and revisions after sacral 2 alar iliac screw and iliac screw fixation for sacropelvic fixation in pediatric and adult populations: Systematic review and meta-analysis. World Neurosurg 132:408-420.e1, 2019

20. Kim YJ, Bridwell KH, Lenke LG, Cho KJ, Edwards CC, 2nd, Rinella AS: Pseudarthrosis in adult spinal deformity following multisegmental instrumentation and arthrodesis. J Bone Joint Surg Am 88:721-728, 2006

21. Kostuik JP: Spinopelvic fixation. Neurol India 53:483-488, 2005

22. Lindsey DP, Kiapour A, Yerby SA, Goel VK: Sacroiliac joint fusion minimally affects adjacent lumbar segment motion: A finite element study. Int J Spine Surg 9:64, 2015

23. McGirt MJ, Corn C, Crosby C, Even J, Mencio GA, Devin CJ: Biomechanical analysis of iliac screws versus S2 alar-iliac screws, 27th Annual Meeting of the AANS/CNS Section on Disorders of the Spine and Peripheral Nerves. J Neurosurg 115: A409, 2011
24. Modi HN, Suh SW, Song HR, Yang JH, Jajodia N: Evaluation of pelvic fixation in neuromuscular scoliosis: A retrospective study in 55 patients. Int Orthop 34:89-96, 2010

25. O'Brien JR, Yu W, Kaufman BE, Bucklen B, Salloum K, Khalil S, et al.: Biomechanical evaluation of S2 alar-iliac screws: Effect of length and quad-cortical purchase as compared with iliac fixation. Spine (Phila Pa 1976) 38:E1250-E1255, 2013

26. Shen FH, Mason JR, Shimer AL, Arlet VM: Pelvic fixation for adult scoliosis. Eur Spine J 22 Suppl 2:S265-S275, 2013

27. Sponseller PD, Zimmerman RM, Ko PS, Pull Ter Gunne AF, Mohamed AS, Chang TL, et al.: Low profile pelvic fixation with the sacral alar iliac technique in the pediatric population improves results at two-year minimum follow-up. Spine (Phila Pa 1976) 35:1887-1892, 2010

28. Tsuchiya K, Bridwell KH, Kuklo TR, Lenke LG, Baldus C: Minimum 5-year analysis of L5-S1 fusion using sacropelvic fixation (bilateral S1 and iliac screws) for spinal deformity. Spine (Phila Pa 1976) 31:303-308, 2006

29. Yoshihara H: Surgical options for lumbosacral fusion: Biomechanical stability, advantage, disadvantage and affecting factors in selecting options. Eur J Orthop Surg Traumatol 24 Suppl 1: S73-S82, 2014

30. Zhu F, Bao HD, Yuan S, Wang B, Qiao J, Zhu ZZ, et al.: Posterior second sacral alar iliac screw insertion: anatomic study in a Chinese population. Eur Spine J 22:1683-1689, 2013 